Available online @ https://jiem.jnnce.ac.in https:www.doi.org/10.37314/JJEM.2020.040206 Indexed in International Scientific Indiexing (ISI) Impact factor: 1.025 for 2018-19 Published on: 30 March 2020

\title{
Design, Development and Installation of Polygon Profile Cutting Attachment for CNC Turning Centre
}

\author{
Raghavendra $\mathbf{H}^{1 *}$, Shanti Kiran $\mathbf{M}^{2}$ \\ ${ }^{1 *, 2}$ Department of Mechanical engineering, \\ JNN College of Engineering, Shimoga-577204, Karnataka, India \\ raghebbar@jnnce.ac.in, shanthikiranm@jncne.ac.in
}

\begin{abstract}
A polygon cutting attachment has been designed, developed and installed in the existing computer numerical control (CNC) turning center using conceptual design. The working of polygon cutting attachment is checked by performing some machining operation. Thus the CNC turning center becomes multifunctional and flexible for performing turning operations as well as milling operations like polygon profile cutting with presently developed attachment. The attachment is compact, detachable, portable unit and is capable of doing many operations that requires special purpose machines. This powered, variable speed precision tool attachment can be mounted in any position on the turret, table, ram of CNC turning center. Thus with two directional feed table, the attachment becomes complete precision machine tool for CNC turning center.
\end{abstract}

Keywords: Polygon profile cutting, CNC turning centre, turret

\section{Introduction}

Computer numerical control (CNC) turning machines are the lathes with built in facility for automation. These machines are capable of making the operations related to turning, where two or three axes of the tool should be controlled to obtain the required cutting path simultaneously. A machine operator is usually required to change tools and also load and unload the work components and $\mathrm{CNC}$ milling center perform only milling operations. [1]. Thus milling cannot be done in CNC turning center and turning operation cannot be done in CNC milling machine. Thus the combination of these turning and milling operation in single machine is quite innovative and the proposed work is regarding the development of the attachment for CNC turning center in which we can perform milling operation, especially polygon profile cutting, otherwise the work piece has to be moved for special purpose machine for performing this operation [2]. The proposed work is designing and developing a tool attachment to carry out these three operations. Polygon profile cutting is machining of the circular work piece to get the polygon surfaces. It may be square, hexagon, octagon and also odd edges. These can be done easily using the normal CNC turning center and the developed attachment with minimum cycle time, lower machining time and higher production rate. The primary concern with the attachment for lathe is the ability to position them accurately relative to work piece and assure that they remain in the position during the milling operation. The turning mill center incorporates fully automated head changing technology to make the machining process automatic and the control system helps in maintaining safety of personnel and also equipment.

\section{Methodology}

\subsection{Problem Identification}

Existing computer numerical control (CNC) 
turning center is capable of performing single operation at a time that is only turning operation. If component being machined requires milling and polygon profile cutting operation the component need to be shifted to polygon profile cutting operation without shifting the component from one machine to other.

\subsection{Study of the Existing CNC Machine} In the existing $\mathrm{CNC}$ machine shown in figure 1 only turning operation was carried out. Control system is FANUC Oi-Mate-TD. Its specification is, between center lengths is $280 \mathrm{~m}$, maximum machining diameter is 140 $\mathrm{mm}$, maximum turning length is $200 \mathrm{~mm}$ and optimum turning diameter is $80 \mathrm{~mm}$. The spindle parameters are as follows: full power range 1000-3000 rpm, where as standard spindle speed is $4000 \mathrm{rpm}$. The maximum bar capacity is $25 \mathrm{~mm}$. the work holding standard chuck size is $135 \mathrm{~mm}$. the number of stations is 8 where in attachment was replaced instead of one among many turning tools. The maximum bore diameter is $32 \mathrm{~mm}$.

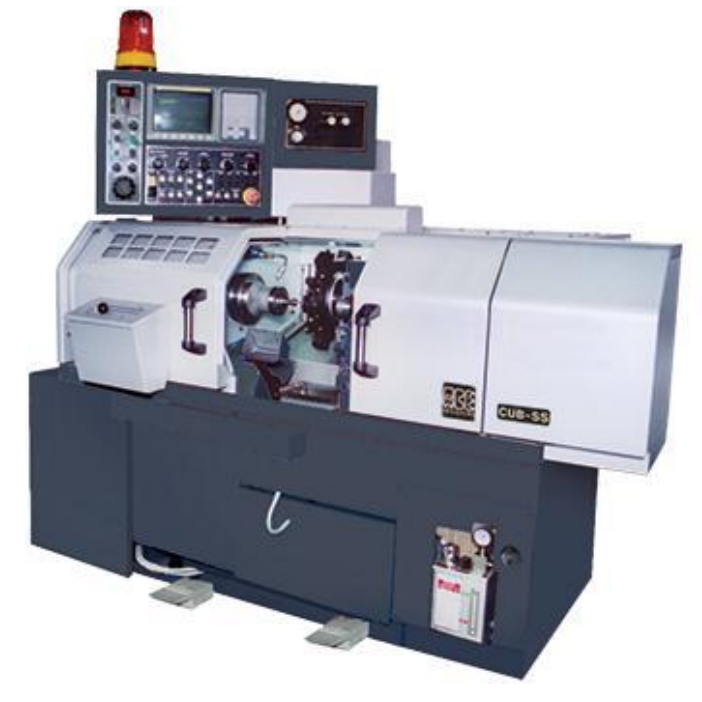

Figure 1: FANUC Oi-Mate-TD CNC Turning center

\subsection{Polygon Profile Cutting Attachment}

The different parts of polygon cutting attachment are explained in the following section.

Bracket-Bracket was designed for holding the motor to the tool station which was designed with respect to the axis.

Eliminator-Eliminator is the device used for another conventional milling or CNC milling to carry out the operation.[3]. This process is time consuming and hence it is required to integrate an attachment to the $\mathrm{CNC}$ in order to carry out turning and milling as well as reducing the output voltage and it converts alternating current to direct current. Since we have used DC motor, it is necessity to get direct current for actuating the motor. Thus eliminator is used.

Adapter-Adapter is the component used to hold the milling cutter from the motor shaft with the help of the collar.

Collar/Bush-Collar/Bush is a cylindrical part fitted on a shaft to prevent sliding (axial) movement also transfers the rotary motion to milling cutter with the help of adapter.

\section{Design \& Fabrication of Milling Attachment}

\subsection{Calculation of motor power}

According to Sandwick coromant standards for milling, actual cutting power $(\mathrm{kW})$ is given by equation (1).

$$
P=\frac{a_{p} \times a_{c} \times V_{f} \times K_{c}}{60 \times 10^{6}}
$$

where,

$$
\begin{aligned}
& a_{p}=\text { depth of cut, } 1 \mathrm{~mm} \\
& a_{c}=\text { cutting width, } 20 \mathrm{~mm} \\
& V_{\mathrm{f}}=\text { table feed per minute, } 60 \mathrm{~mm} / \mathrm{min} \\
& \text { (from Sandwick coromant standards) } \\
& \mathrm{K}_{\mathrm{c}}=\text { specific cutting force, } 2030 \mathrm{~N} / \mathrm{mm}^{2} \\
& \text { (From Sandwick coromant standards) }
\end{aligned}
$$

Substituting the aforementioned values, the actual cutting power is found to be $0.0406 \mathrm{~kW}$.

\subsection{Calculation of feed per tooth}

According to Sandwickcoromant standards for milling, feed/tooth $\left(f_{z}\right)$ is given by equation (2)

$$
f_{z}=\frac{V_{f}}{Z \times N}
$$

where,

$\mathrm{z}$ is the number of teeth (4 in this case). 
From equation (2), $\mathrm{f}_{\mathrm{z}}$ was found to be 0.0785 $\mathrm{mm} /$ tooth, and the corresponding value of $\mathrm{V}_{\mathrm{c}}$ from Sandwickcoromant standards is 60 $\mathrm{mm} / \mathrm{min}$.

\subsection{Spindle speed of the motor}

The spindle speed of the motor is given by equation (3)

$$
N=\frac{1000 \mathrm{xVc}}{\pi \mathrm{D} 1}
$$

where,

$\mathrm{D}_{1}=$ diameter of the cutter used, $100 \mathrm{~mm}$

The spindle speed of motor obtained from equation (3) was found to be $190.98 \mathrm{rpm}$.

The different speed was selected based on the milling cutter used for machining purpose. The rpm was selected from sandvik coromant standards for milling operations. At low speed $275 \mathrm{rpm}$ and at high speed $650 \mathrm{rpm}$ was selected.

\section{Bracket Design}

Figure 2 is a bracket, which holds the attachment in the turret of CNC turning centre.
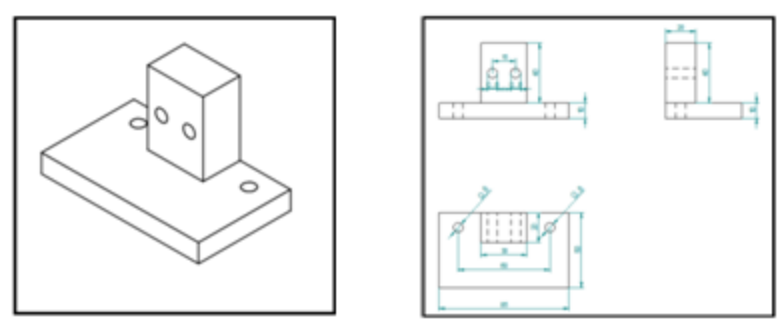

Figure 2: Bracket

The thickness of a rectangular plate subjected to uniform load, according to Grashoff law is given by equation (4). (Referred from design data handbook by $\mathrm{K}$ Mahadevan and Balaveerareddy.

$$
t=a b c_{3}\left[\frac{p}{f\left(a^{2}+b^{2}\right)}\right]^{\frac{1}{2}} \mathrm{~mm}
$$

where,

$\mathrm{t}=$ thickness of plate, $\mathrm{mm}$

$\mathrm{a}=$ length of the plate $=155 \mathrm{~mm}$,

$\mathrm{b}=$ breadth of the plate $=95 \mathrm{~mm}$,

$c_{3}=0.49$ (constant for bending from data hand book),

$\mathrm{P}=$ weight of the motor,

$\mathrm{f}=$ allowable stress in $\mathrm{MPa}$

Material used is mild steel and allowable stress in bending is $162.5 \mathrm{MPa}$

\section{Collar/ Bush}

Figure 3 shows the collar/ bush is a cylindrical feature on a part fitted on the shaft used to prevent sliding (axial) movement and also supports to mount the cutter with the help of adapter. The component is made of mild steel with counter bore and drill on the surface to fix the pins to prevent sliding actions.
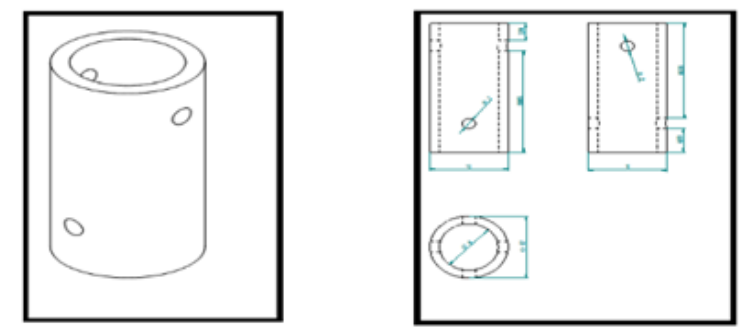

Figure 3: Collar/Bush

\section{Adapter}

Adapter has been designed for holding the milling cutter from the motor shaft. For different size milling cutter suitable adapter or drill chuck should be used, but resulting in wobbling as the length of the tool increases. Hence only adapter is used in proposed work. The adapter is made of mild steel. The isometric and orthographic views of adapter are shown in the figure $4 \mathrm{a}$ and figure $4 \mathrm{~b}$.
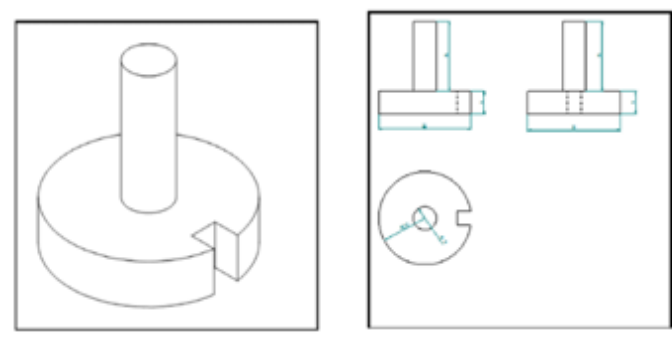

Figure 4: Adapter 


\section{Fabrication of Milling Attachment}

The steps involved in the fabrication of milling attachment are explained as follows:

1. Bracket was designed with reference to the machine center axis from the existing CNC machine.

2. The motor selected was DC motor and was based on the available space as per the requirement.

3. Initially the dimension of motor shaft was noted. Based on the dimension of the milling cutter, the adapter was designed. Finally adapter was designed for the purpose of holding milling cutter.

4. The milling cutter was selected according to the standard dimensions available. To hold the adapter collar/bush was designed. This connects the motor shaft and adapter and therefore connects with milling cutter for the rotations.

5. The attachment was designed in such a way that it was capable of performing both flat and cylindrical operations.

\section{Results and discussion}

The polygon profile cutting attachment has been designed and fabricated and installed in the existing CNC turning center as shown in figure 5. Polygon profiles made with the attachment for different material are discussed in the following section. [4]

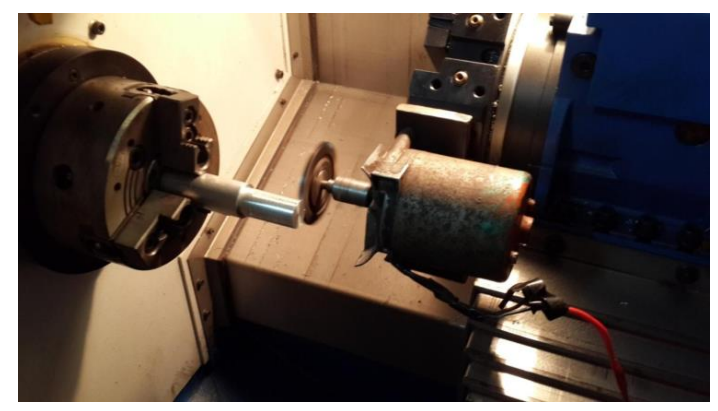

Figure 5: Polygon profile cutting attachment
Machining was carried out on materials such as aluminium, brass and copper. For these materials the component shape we considered is as shown in the figure 6. The isometric and orthographic view is shown in which a square profile have been considered.
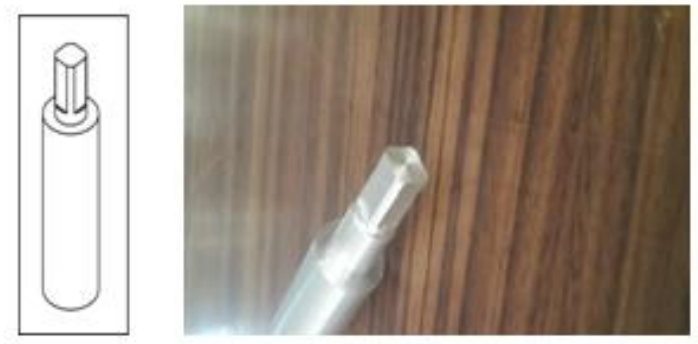

Figure 6: Specimens milled with the attachment

\subsection{Hardness Test of Materials}

Hardness of the materials was determined by Rockwell hardness tester and the hardness values of different specimens are given in Table 1

Table 1: Hardness of components

\begin{tabular}{|c|c|c|c|c|c|}
\hline $\begin{array}{c}\text { Sl. } \\
\text { No }\end{array}$ & Material & $\begin{array}{c}\text { Load } \\
\text { kgf }\end{array}$ & Indentor & $\begin{array}{c}\text { Scale } \\
\text { Type }\end{array}$ & $\begin{array}{c}\text { Hardness } \\
\text { HRC }\end{array}$ \\
\hline 1 & Aluminium & 100 & Ball & B & 86 \\
\hline 2 & Copper & 100 & Ball & B & 97 \\
\hline 3 & Brass & 100 & Ball & B & 99 \\
\hline
\end{tabular}

\subsection{Consistency and accuracy check chart for square milling}

The accuracy and consistency of the attachment was checked by performing milling operation on different components by giving the total depth of cut of $2 \mathrm{~mm}$. [5] The results of the consistency and accuracy of the specimens are given in table 2, 3 and 4. Graph has been plotted based on above values to observe the consistency of material removal of the component.

These graphs are shown in figures 7, 8 and 9 respectively for aluminium, copper and brass.

Table 2: Material removed expressed in $\mathrm{mm}$ for aluminium specimen

\begin{tabular}{|l|l|c|c|c|c|}
\hline $\begin{array}{c}\text { Sl. } \\
\text { No. }\end{array}$ & Material & $\begin{array}{c}\mathbf{1}^{\text {st }} \\
\text { face }\end{array}$ & $\begin{array}{c}\mathbf{2}^{\text {nd }} \\
\text { face }\end{array}$ & $\begin{array}{c}\mathbf{3}^{\text {rd }} \\
\text { face }\end{array}$ & $\begin{array}{c}\mathbf{4}^{\text {th }} \\
\text { face }\end{array}$ \\
\hline 1 & Aluminium & 1.96 & 1.91 & 1.90 & 1.91 \\
\hline 2 & Aluminium & 1.95 & 1.96 & 1.94 & 1.93 \\
\hline 3 & Aluminium & 1.94 & 1.96 & 1.92 & 1.91 \\
\hline
\end{tabular}


Table 3: Material removed expressed in $\mathrm{mm}$ for copper specimen

\begin{tabular}{|l|l|c|c|c|c|}
\hline $\begin{array}{c}\text { Sl. } \\
\text { No. }\end{array}$ & Material & $\begin{array}{c}\mathbf{1}^{\text {st }} \\
\text { face }\end{array}$ & $\begin{array}{c}\mathbf{2}^{\text {nd }} \\
\text { face }\end{array}$ & $\begin{array}{c}\mathbf{3}^{\text {rd }} \\
\text { face }\end{array}$ & $\begin{array}{c}\mathbf{4}^{\text {th }} \\
\text { face }\end{array}$ \\
\hline 1 & Copper & 1.99 & 1.94 & 1.94 & 1.91 \\
\hline 2 & Copper & 1.98 & 1.94 & 1.91 & 1.90 \\
\hline 3 & Copper & 1.98 & 1.93 & 1.93 & 1.91 \\
\hline
\end{tabular}

Table 4: Material removed expressed in $\mathrm{mm}$ for brass specimen

\begin{tabular}{|l|l|c|c|c|c|}
\hline $\begin{array}{c}\text { Sl. } \\
\text { No. }\end{array}$ & Material & $\begin{array}{c}\mathbf{1}^{\text {st }} \\
\text { face }\end{array}$ & $\begin{array}{c}\mathbf{2}^{\text {nd }} \\
\text { face }\end{array}$ & $\begin{array}{c}\mathbf{3}^{\text {rd }} \\
\text { face }\end{array}$ & $\begin{array}{c}\mathbf{4}^{\text {th }} \\
\text { face }\end{array}$ \\
\hline 1 & Brass & 1.97 & 1.93 & 1.92 & 1.90 \\
\hline 2 & Brass & 1.96 & 1.97 & 1.93 & 1.91 \\
\hline 3 & Brass & 1.97 & 1.97 & 1.93 & 1.92 \\
\hline
\end{tabular}

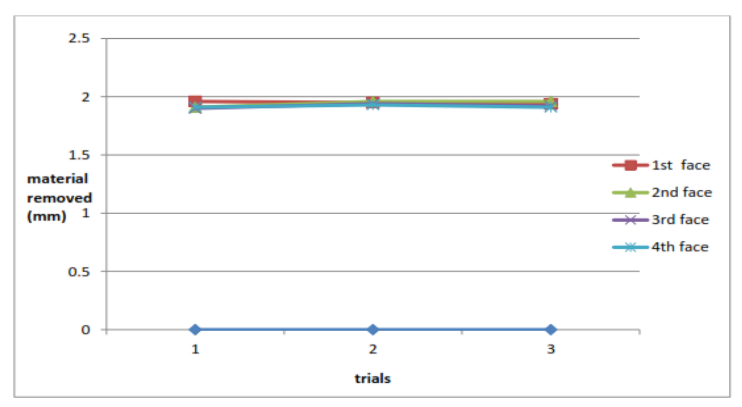

Figure 7: Consistency of machining for aluminium specimen

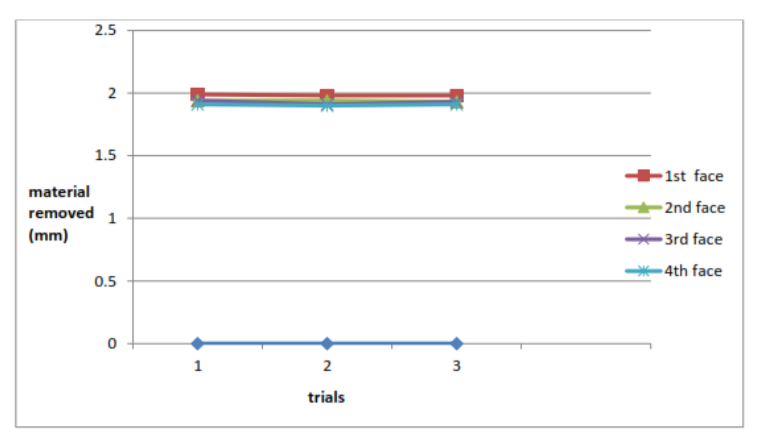

Figure 8: Consistency of machining for Copper specimen

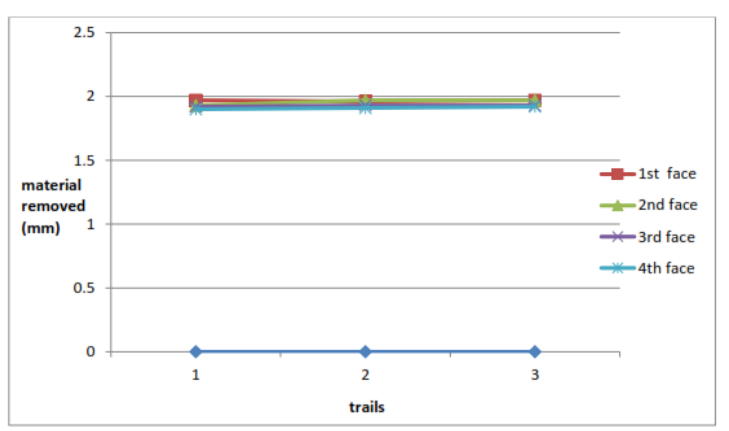

Figure 9: Consistency of machining for Brass specimen

This shows the consistency and accuracy of the milling attachment with respect to depth of cut was achieved in all the trials. Thus the required shape (square, hexagon and so on) is obtained.

\subsection{Testing Dimension Accuracy}

Number of components ware machined for checking the dimensional accuracy and the results are given in table 5 .

Table 5 Dimensions obtained for accuracy check

\begin{tabular}{|c|c|}
\hline No. of components & A-B $(\mathrm{mm})$ \\
\hline 1 & 11.99 \\
\hline 2 & 12.02 \\
\hline 3 & 12.05 \\
\hline 4 & 11.95 \\
\hline 5 & 11.93 \\
\hline 6 & 11.97 \\
\hline
\end{tabular}

Based on these data graph has been plotted (figure 10) to study the dimension accuracy which comes within tolerable limits. In the graph $\mathrm{x}$-axis represents number of components machined, $y$-axis represents the thickness of the required material in $\mathrm{mm}$. A-B represents the distance between one face to another face which are parallel. The graph indicates the dimension accuracy which is within the tolerable limits whereas tolerable limit is considered as $\pm 0.1 \mathrm{~mm}$ 


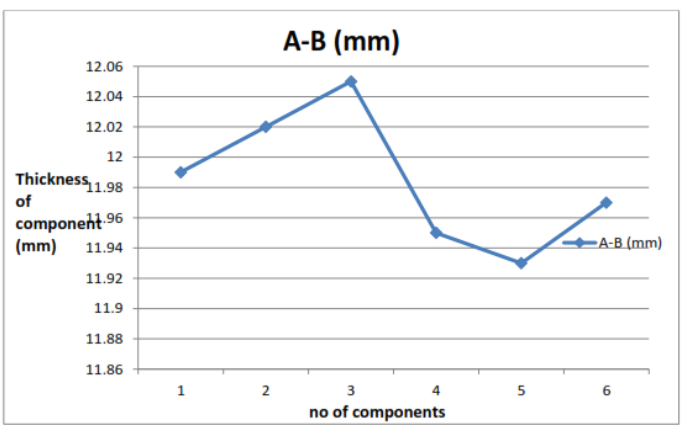

Figure 10: Graph representing dimensional accuracy

\subsection{Surface Roughness Testing}

Machining each material gave different surface finish and cycle time while machining with high speed and low speed. The number of trials was carried out with high speed and low speed but the required torque was not obtained and hence the machining was done at constant speed with high rpm. For the milling operation the cutter was selected based on the specification of the machine and diameter of the work piece used. Number of trials was carried out for different feed rates and same depth of cut. The surface roughness test was carried out by surface testing machine SURFCOM130A (figure 11.) for each component and it was compared with the turning operation which was done in the same machine. The surface roughness values of the components are mentioned in the table 6.

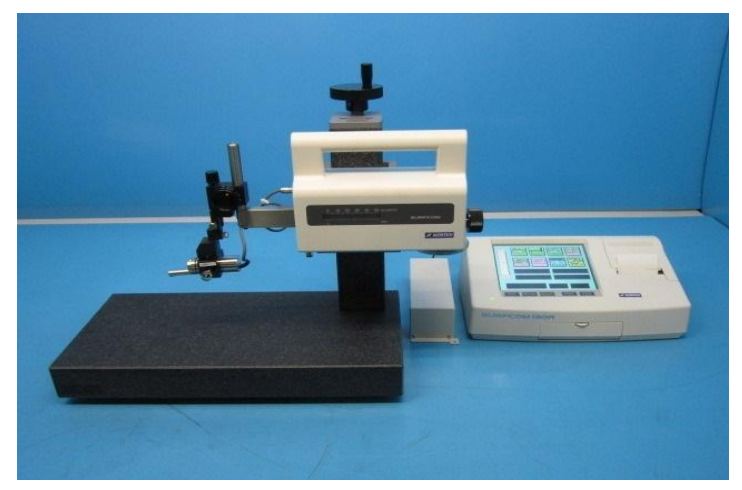

Figure 11: SURFCOM130A surface roughness tester

Specifications of SURFCOM130A

Travel length $=8 \mathrm{~mm}$, Cutoff $=0.8 \mathrm{~mm}$

With high RPM and $0.5 \mathrm{~mm}$ depth of cut, the results obtained are given in table 6
Table 6: Surface finish and cycle time for aluminium, copper and brass

\begin{tabular}{|c|c|c|c|c|}
\hline \multirow{2}{*}{$\begin{array}{c}\text { Feed } \\
\mathrm{m} / \mathrm{min}\end{array}$} & \multicolumn{3}{|c|}{ Surface finish $R a$ in $\mu \mathrm{m}$} & \multirow{2}{*}{$\begin{array}{l}\text { Cycle } \\
\text { time } \\
\text { in Sec }\end{array}$} \\
\hline & Aluminium & Copper & Brass & \\
\hline 15 & 2.859 & 1.89 & 1.23 & 350 \\
\hline 10 & 2.361 & 1.73 & 1.07 & 480 \\
\hline 7 & 2.193 & 1.58 & 1.02 & 720 \\
\hline 5 & 1.826 & 1.31 & 0.87 & 940 \\
\hline
\end{tabular}

Previously the components were subjected to turning operation in the same $\mathrm{CNC}$ machine and the surface finish was tested at the feed rate of $10 \mathrm{~mm} /$ revolution which gave the results as

Aluminium $=2.13$

Brass $=1.41$

Copper $=1.75$

Comparing these values (in $\mu \mathrm{m}$ ) which were obtained by turning operation to the values obtained by carrying out the operation by attachment shows the similar capability of machining. Thus the machine attachment achieves the machining ability with good surface finish and accuracy also shows that surface finish will be good with the material having more hardness.

\subsection{Correlation between hardness and surface roughness}

Residual stress on the machined surface is of compressive stress, but it changes to tensile stress as the hardness increases. Hardness of the metal and the surface roughness are negatively associated and hence they are inversely proportional. So experiments have proved that increase in hardness resulted in good surface finish. Since hardness is the measure of resistance offered against the indentation or scratching, surface roughness has always been influenced by the hardness of the metal. It is concluded that the coefficient of friction and wear are depending on the roughness. The higher value of friction is attributed to the higher value of hardness. The friction increases as the surface roughness increases, but the surface roughness is influenced by hardness of the metal and it correlates inversely with load. Table 7 shows the details of hardness of the materials and 
surface finish obtained while performing milling with feed rate of $10 \mathrm{~m} / \mathrm{min}$. Thus, surface roughness is low with higher hardness of the material.

Table 7 Surface roughness for different materials

\begin{tabular}{|l|c|c|c|}
\hline & Aluminium & Copper & Brass \\
\hline Hardness & 86 & 97 & 99 \\
\hline $\begin{array}{l}\text { Surface } \\
\text { Roughness } \\
(\mu \mathrm{m})\end{array}$ & 2.36 & 1.73 & 1.07 \\
\hline
\end{tabular}

\subsection{Rate of Production}

Rate of production is calculated by considering the machining parameters like feed rate $10 \mathrm{~m} / \mathrm{min}$, depth of cut $0.5 \mathrm{~mm}$ and cutter speed of $650 \mathrm{rpm}$. Cycle time for machining single component is $=8 \mathrm{~min} /$ component. If the working hours per shift are $8 \mathrm{hrs}$ and we can produce 60 components/ shift.

\section{Conclusion}

The following conclusions are drawn from the present work which involves the design and development of polygon attachment for a $\mathrm{CNC}$ turning center.

- Polygon profile cutting attachment has been developed successfully.

- Polygon profile cutting operations can be performed in the existing CNC turning center, in which only turning operation was able to carry out earlier.

- The performance of the proposed work was validated by testing surface finish using comparative analysis where in the result yields the surface finish within acceptable limit.
- The result concludes that the present work is more suitable for milling of non ferrous materials.

- The operation on aluminium shows slightly rough compared to brass and copper materials.

\section{References}

1. S.-H. Suh,J.-J. Lee and S.-K.Kimm Multiaxis machining with additional-axis NC system: Theory and development, The International Journals of Advanced Manufacturing Technology, Vol. 14, Issue 12, 1998, 865-875.

2. V. Roy, S. Kumar, Development of Lathe Attachment for a CNC Machine, Journal of The Institution of Engineers (India): Series C, Vol. 94, Issue 2, April 2013, 187-195.

3. J. Chen, N. Hundal, A Systematic Approach for Identifying the Turning Center Capabilities with Vertical Machining Center in milling operation. International Journal of Industrial and Manufacturing Engineering Vol:8, No:5, 2014, 892-901.

4. Matthew C. Frank Richard A. Wysk, Sanjay B. Joshi, Rapid planning for CNC milling-A new approach for rapid prototyping, Vol. 23, Issue 3, 2004, 242-255.

5. P. R. Gibson, K. Hoang, Automatic statistical process control of a CNC turning centre using tool offsets and tool change, The International Journal of Advanced Manufacturing Technology 1994 Vol. 9, Issue 3, 147-155. 